\title{
Pyrolysis of plastic waste for production of heavy fuel substitute: a techno- economic assessment
}

\author{
Antzela Fivga*a and Ioanna Dimitriou ${ }^{\mathrm{b}}$ \\ a Department of Chemical and Biological Engineering, University of Sheffield, Mappin Street, Sheffield, S1 3JD, UK \\ bDepartment of Chemical and Environmental Engineering, Faculty of Engineering, University of Nottingham, Nottingham, \\ NG7 2RD, UK \\ *Corresponding author. E-mail address: antzela@fivga.com (A. Fivga).
}

\begin{abstract}
Pyrolysis is widely seen as a promising technology for converting plastic waste into a wax/oil product which can be used as a heavy fuel oil substitute or as raw material by the petrochemical industry. A pyrolysis plant with a capacity of $100 \mathrm{~kg} / \mathrm{h}$ plastic waste is modelled in the process simulation software Aspen HYSYS. The production costs of the pyrolysis fuel product is estimated at $£ 0.87 / \mathrm{kg}$ which is $58 \%$ higher than current market prices; therefore, a scaling-up analysis is also carried out to determine the plant capacity for which the pyrolysis process is economically feasible. The fuel production costs of the scaled-up cases considered are approximately 2.2 - 20.8 times lower than the existing market prices of residual fuel oil, indicating their economic feasibility. For the $1000 \mathrm{~kg} / \mathrm{h}$ and $10,000 \mathrm{~kg} / \mathrm{h}$ plant capacity cases the facility needs to operate approximately four years and one year respectively, to recover the capital investment, while the $100,000 \mathrm{~kg} / \mathrm{h}$ case produces revenue and has a positive NPV within year one. A sensitivity analysis is also carried out revealing that the fuel production rate is the most sensitive parameter for the $100 \mathrm{~kg} / \mathrm{h}$ plant, as well as the scaled-up plants.
\end{abstract}

Keywords: Pyrolysis, Aspen HYSYS, Techno-economic analysis, Plastic waste, Process modelling

\section{Introduction}

The amount of plastic waste generated every year is estimated to be increasing at a rate of $3.9 \%$ per year ${ }^{1}$. This, combined with the existing amount of municipal solid waste, make the management of plastic waste an ever-increasing problem. Additionally, owing to many countries' increasing desire for energy independence, there is a growing interest in alternatives to fossil fuels with waste derived feedstocks, like waste biomass and plastic waste, receiving most of the attention mainly due to their abundance and environmental benefits.

In 2013, 299 million tons of plastic waste was generated globally, with the European Union alone generating more than 25.2 million tons of post-consumer plastic waste each year ${ }^{1}$. Of this, around $26 \%$ is recycled, $36 \%$ is recovered by energy recovery processes, such as incineration, and the remainder is landfilled. Incinerating plastics can cause several environmental issues, such as dioxins formation, fly ash, production of sulphur and nitrogen oxides, and other toxins ${ }^{2,3}$. Additionally, if not disposed of properly, plastics can end up in the oceans negatively affecting the marine ecosystems ${ }^{4}$. To deal with those issues, the European Union (EU) is promoting plastics recycling by requiring $65 \%$ of municipal and $75 \%$ of packaging waste, including plastics, to be recycled by $2030^{5,6}$.

Convectional mechanical recycling techniques cannot recycle all types of plastic waste due to their contamination with food, dirt, paper labels, and polymer mixtures which makes energy recovery technologies an attractive alternative ${ }^{7}$. Therefore in recent years, thermochemical conversion technologies such as pyrolysis, incineration and gasification, have gained significant attention for the management of plastic waste. Specifically, pyrolysis has shown significant advantages over the others, 
since it produces reduced gaseous pollutants, due to the absence of $\mathrm{O}_{2}$ in the process. The pyrolysis process is also promising because its main product is a wax/oil, which can be used as a heavy fuel substitute or as raw material for resale into the petrochemical industry, along with production of char and gases which can be sold or further processed to add value to the overall process. ${ }^{8,9}$. This is in contrast with incineration which only generates power and heat, in addition to its negative environmental impact. Fuel mass yields from the pyrolysis process are extremely promising for energy production, since they vary from 84.5 to $89.2 \mathrm{wt} . \%^{10}$ for polyethylene (PE), 93 to $96 \mathrm{wt} \%$ for polystyrene (PS), and for polypropylene (PP) typical yields are approximately $84 \mathrm{wt} \% \%^{11,12,13,14}$.

Several experimental studies of plastic waste pyrolysis have investigated the effect of operating parameters ${ }^{15,16}$, reactor type, feedstock composition ${ }^{12}$, and pollutants on fuel quality and composition ${ }^{17}$. These have shown the potential of the process for the dual purpose of waste management and energy production. In contrast, there are very few published studies which have examined the technoeconomic potential of plastic waste pyrolysis. Sahu at al. used the process simulation software Aspen Plus to investigate the potential of catalytic cracking of waste plastic to produce fuel oils in Malaysia ${ }^{18}$. A rate of return (ROR) analysis was carried out which showed that the process can be profitable for a large scale plant with an annual feed rate of 120,000 tonnes. Additionally, it was found that the payback period for the large scale plant was 1.42 years which corresponds to a ROR of $35.97 \%$. This work included a sensitivity analysis study on the annual profits, although this was done only for the product sale price ignoring other important technical and economic parameters (e.g. capital investment, raw material costs). Sayal et al. developed a process simulation model to investigate the conversion of waste plastic to hydrocarbons using the process simulation software Aspen HYSYS; however, an economic feasibility study of the process was not conducted ${ }^{19}$. Both studies focused on pyrolysis of plastic waste to produce liquid transport fuels (i.e. gasoline, diesel). Automotive transport fuels derived from alternative feedstocks are generally characterised by high cleaning and upgrading requirements before they can be used in standard vehicle engines. The additional plant equipment and raw materials needed for improving the quality of these fuels further increase the overall costs making this plastic waste pyrolysis route less attractive for potential investors.

The present work focuses on investigating the technical and economic feasibility of a plastic waste pyrolysis plant for the production of fuel oil which can be used as a heavy fuel oil substitute or as raw material by the petrochemical industry. As such, it requires much less refining and thus offers lower overall production costs than road transport fuels, making this plastic waste pyrolysis route potentially more attractive for public and private investors. The main aim is to identify the key factors which influence the economic competitiveness of plastic waste as alternative feedstock for fuel oil production via a comprehensive process modelling and economic analysis study. The majority of household plastic waste consists of polyethylene, polypropylene, and polystyrene and this mixture was used in this study as the reference feedstock ${ }^{20}$.

An overview of the pyrolysis process evaluated in this paper is presented in the following section. Section 3 and 4 summarise the methodology for the process modelling and the economic assessment, respectively. The results of this study are presented in Section 5 along with a sensitivity analysis which is carried out to examine the effect of key process parameters on the production cost of the pyrolysis fuel product.

\section{Process description}

Pyrolysis is a process where plastic is thermally cracked due to rapid heating in the absence of oxygen, reducing the plastics long polymer chains into much shorter hydrocarbons. The process takes place in 
four stages which are: initiation, transfer, decomposition and termination, resulting in the production of vapours and $\operatorname{char}^{21}$. These pyrolysis vapours include both condensable and non-condensable gases. The condensation of the condensable vapours forms the pyrolysis wax/oil which is a complex combination of the thermal cracking products of each plastic type. To add to this complexity, interreactions between these primary thermal cracking products occur resulting in the production of secondary products ${ }^{9,22}$. Additionally, char and non-condensable gases are also produced but these are simply by-products of the pyrolysis process.

The pyrolysis system examined in this study converts plastic waste to a heavy fuel substitute or a petrochemical feedstock, as shown in Figure 1. The process was developed by a recycling company based in the UK. It consists of four functional units: pyrolysis of plastic waste, char separation, collection of the pyrolysis fuel oil and combustion of the by-production a secondary fluidised bed reactor which generates the thermal energy required by the pyrolysis reactor. The base case scenario considered in this study has a capacity of $100 \mathrm{~kg} / \mathrm{h}$ of plastic waste which is the same as the capacity of the pyrolysis pilot plant developed by the recycling company.

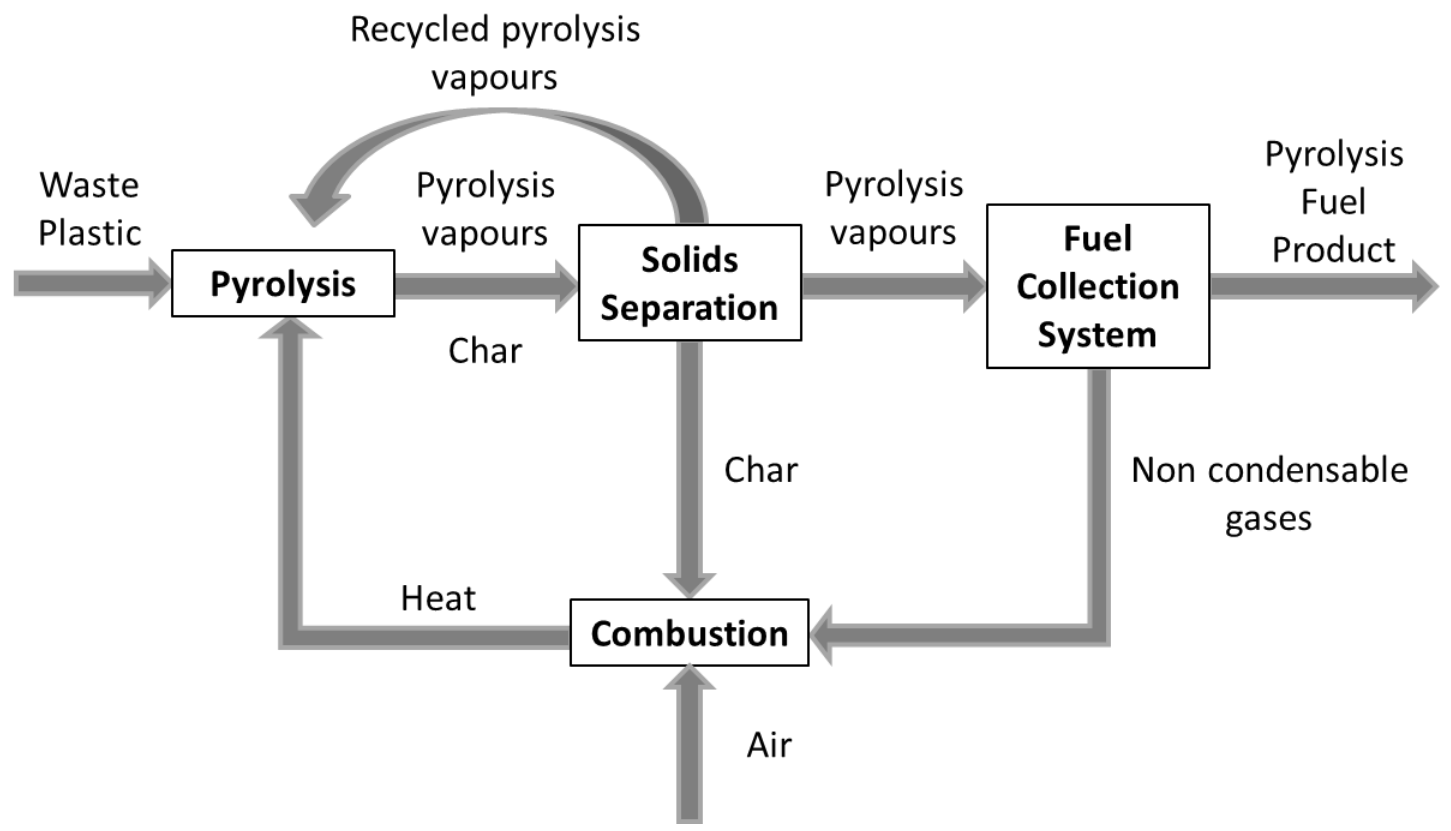

Figure 1: An overview of the pyrolysis system for the production of fuel.

The pyrolysis process occurs in a fluidised bed reactor, in an inert atmosphere, at atmospheric pressure and at a fixed reaction temperature. Thermal cracking of plastics occurs within the temperature range of $450-650^{\circ} \mathrm{C}$, depending on the heating rate and plastics type ${ }^{23,24}$, with the reaction temperature strongly influencing the pyrolysis product yields ${ }^{22,25,15}$. The selection of a fluidised bed reactor was due to its high heat transfer rates and low vapour residence time to be able to achieve higher liquid/wax yields ${ }^{26}$. For this study, the pyrolysis reactor temperature was set at $530^{\circ} \mathrm{C}$, to achieve higher liquid/wax yields, according to the current literature and experimental data from the recycling company ${ }^{14,15,27}$. After the exit of the pyrolysis products from the reactor, the temperature is kept at $530^{\circ} \mathrm{C}$ and the vapours enter the solids separation section where char is separated, by using a ceramic hot vapour filter unit (HVF), and delivered to the combustor. The pyrolysis vapours are partially recycled back to the pyrolysis reactor with a sufficient flow rate to provide three times the minimum fluidising velocity to the bed ${ }^{28}$. This avoids the need for nitrogen as a fluidisation gas and increases the energy efficiency of the overall process. Nitrogen is used only at start-up of the plant. 
The recycled pyrolysis vapours provide the fluidised gas for the pyrolysis reactor and partially cover its heat requirements, while the non-recycled pyrolysis vapours are kept above their dew point until they reach a series of four heat exchangers and separators where the condensed fuel is collected.

The exit temperature of the first heat exchanger, which collects the heavier pyrolysis vapours, is set at $400^{\circ} \mathrm{C}$. The vapours are then recycled to the pyrolysis reactor for further cracking. The remaining nonrecycled pyrolysis vapours enter a series of heat exchangers and separators at $200^{\circ} \mathrm{C}, 80^{\circ} \mathrm{C}$ and $25^{\circ} \mathrm{C}$. Water is provided in a closed loop at $40^{\circ} \mathrm{C}$ to the first three exchangers and at $10^{\circ} \mathrm{C}$ to the fourth exchanger. Pressure drop across the heat exchangers and separators is assumed to be $2 \mathrm{kPa}$. Standard shell and tube heat exchangers are used with the exception of the fourth one which is a double pipe heat exchanger. The condensed fuel from each separator is delivered to a closed tank, where it forms the pyrolysis fuel product. The mass flow rate of each condensed fuel stream is continuously monitored so that adjustments can be made to the operating parameters in case the flow rate varies from the design specifications due to feedstock variations. The fuel tank acts as a buffer to balance out these fluctuations and ensure fuel homogeneity.

The remaining non-condensable gases and the separated char are recirculated to a secondary fluidised bed reactor where they are combusted to generate the thermal energy required by the pyrolysis reactor. A fan supplies air at $10 \%$ excess to the fluidised bed combustor and provides the required pressure drop across the fluidised bed.

\section{Process modelling}

\subsection{Process modelling methodology}

The Aspen HYSYS process simulation software ${ }^{29}$ was selected to develop the process flowsheet of the waste plastic pyrolysis process, as well as estimate material balances, energy and utility requirements as the inputs for the techno-economic analysis. The Peng-Robinson thermodynamic property method was used for the process unit operations which is recommended for modelling refinery applications and provides accurate results for hydrocarbon and light gases systems, such as $\mathrm{H}_{2}$ and $\mathrm{CO}_{2}{ }^{30}$.

The plastic waste feedstock is modelled by considering an elemental composition of $85 \mathrm{wt} . \%$ carbon and $15 \mathrm{wt}$. \% hydrogen on dry ash free basis ${ }^{12,31}$. In general, the ash content for PE, PP and PS are lower than $1 \mathrm{wt} . \%$ on a dry basis ${ }^{31,32}$. This was considered too low to significantly affect the overall mass balance of the process and it was, therefore, set to zero. The higher heating value (HHV) of the feedstock is calculated using the following formula ${ }^{33}$ :

HHVdry $(\mathrm{MJ} / \mathrm{kg})=0.3491 * \mathrm{C}+1.1783 * \mathrm{H}+0.1005 * \mathrm{~S}-0.1034 * \mathrm{O}-0.015 \mathrm{~N}-0.0211 \mathrm{~A}$

Where $\mathrm{C}, \mathrm{H}, \mathrm{S}, \mathrm{O}, \mathrm{N}$ and A represent mass percentages on dry basis of carbon, hydrogen, sulphur, oxygen, nitrogen and ash contents of feedstock, respectively.

The lower heating value (LHV) of the feedstock is calculated using the following formula ${ }^{33}$ :

LHVdry $(\mathrm{MJ} / \mathrm{kg})=$ HHVdry $-2.442 * 8.936 * \mathrm{H} / 100$

The HHV of dry plastic waste used in this study is calculated using Eq. 1 and amounts to $47.35 \mathrm{MJ} / \mathrm{kg}$, while the LHV is calculated using Eq. 2 and amounts to $44.07 \mathrm{MJ} / \mathrm{kg}$. This is in agreement with values in literature ${ }^{32,34}$. 
The Aspen HYSYS yield shift reactor is used to simulate the pyrolysis reactor as only product yield data was available. This type of reactor is considered when the reaction stoichiometry or kinetics is unknown, but the product yield is available. The selection of representative model hydrocarbon groups for the pyrolysis fuel is not straight forward since it contains a large amount of different primary and secondary products which depend both on the process operating conditions and the type of the plastic feedstock. Table 1 shows the mass yields considered for the pyrolysis products.

Table 1: Product distribution for the pyrolysis reactor (on feedstock dry ash free basis) ${ }^{\mathrm{a}}$

\begin{tabular}{ll}
\hline Compound & wt.\% \\
\hline Ethane & 6.49 \\
n-Octane & 18.58 \\
n-C14 & 31.86 \\
n-C18 & 15.75 \\
n-C25 & 16.87 \\
n-C30 & 3.45 \\
Char & 7.00 \\
\hline Total & 100 \\
\hline Tany based in the UK, personal communication 2014
\end{tabular}

The model mass yields above had to be slightly modified, before they were used as output for the Aspen HYSYS yield shift reactor, to take into account water gas shift reactions and partial combustion which occur in the pyrolysis reactor. The former take place due to moisture in the feedstock and the latter occur due to air entering the reactor through the feeder.

The Aspen HYSYS yield shift reactor can calculate the thermal energy of the water gas shift reactions and partial combustion which occur in the pyrolysis reactor, but cannot estimate the required energy for the process of pyrolysis. The numerous exothermic and endothermic reactions that take place within the pyrolysis fluidised bed reactor make very complicated the calculation of data on heat transfer. For this reason, the amount of thermal energy needed to pyrolyse $1 \mathrm{~kg}$ of dry waste plastic is calculated by using data from literature and is assumed to be $1316.1 \mathrm{~kJ} / \mathrm{kg}$ approximately ${ }^{11,35}$. The total thermal energy for the pyrolysis reactor, including the values calculated by Aspen HYSYS, amounts to $41.16 \mathrm{~kW}$.

The combustor is simulated using a Gibbs reactor which models single-phase chemical equilibrium by minimizing the Gibbs free energy, subject to atom balance constraints. Light hydrocarbons (non condensable gases) and the pyrolysis char are mixed with air (10\% excess) and fed into the combustor to provide the required energy for the pyrolysis endothermic reactions.

\subsection{Model input validation}

The waste plastics feedstock considered in this study is a mixture of polyethylene, polypropylene and polystyrene, since this mixture comprises the majority of household plastic waste. Product yields can vary due to their dependence on reaction temperature ${ }^{15,16}$, reactor type, feedstock composition ${ }^{12}$ and pollutants ${ }^{17}$. Typical product yields from polyethylene pyrolysis vary from 84.5 to $89.2 \mathrm{wt}$ \% for wax/oil, from 10.2 to 10.9 wt. \% for non condensable gases, and 0.1 to $5.1 \mathrm{wt}$. \% for char ${ }^{11,12,13}$. Yields from polystyrene vary from 93 to $96 \mathrm{wt}$. \% for wax/oil, from 0.04 to $4 \mathrm{wt} \%$ for non condensable gases, and 0.2 to 3 wt. \% for char, while in case of polypropylene typical yields are 84 wt. $\%$ for wax/oil, 15.7 wt. $\%$ for non condensable gases, and 0.25 wt. $\%$ for char $^{11,14}$, which are in close agreement with the product yields used in this study (see Table 1). As it is mentioned in Section 3.1 the Aspen HYSYS yield shift reactor requires the product mass yields to simulate the pyrolysis 
reactor. As can be seen in Table 1, the product yields used for this study are taken from results of experiments performed by a recycling company based in the UK, using their laboratory fluidised bed reactor. To compensate for variations in product yields, a sensitivity analysis has also been carried out in this study, to investigate the effect of different pyrolysis product fuel yields on the economic feasibility of the proposed process.

The pyrolysis product fuel needs to be defined in order to model the process. For this purpose, a number of representative model hydrocarbons/compounds contained in the product fuel were selected to supply thermodynamic data necessary for the calculation of energy balances for the pyrolysis process. The model hydrocarbon groups selected for this study are n-octane, $n-C_{14}, n-C_{18}, n-C_{25}$ and n$\mathrm{C}_{30}$, as shown in Table 1. As discussed above, the selection of representative model hydrocarbon groups for the pyrolysis product fuel is not straight forward due to the fact that the pyrolysis fuel contains a large amount of different primary and secondary products. A typical compound distribution in the wax/oil produced from the pyrolysis of the plastics investigated in this study includes alkanes, alkenes, and low aromatics, ranging from $\mathrm{C}_{7}$ to $\mathrm{C}_{25+}$ compounds ${ }^{9,11,36}$. The fuel produced from pyrolysis of PE can be in the form of wax, due to the long carbon chain structure, depending on operating conditions, but research showed that pyrolysis of a mixture of PE with PP and PS $(50 \% / 25 \% / 25 \%)$ produces a liquid fuel ${ }^{16}$.

\section{Cost estimation methodology}

The software Aspen Process Economic Analyzer (APEA) is used to estimate the capital investment and operating costs for the pyrolysis process plant. APEA is linked to Aspen HYSYS to estimate costs by utilising the output results of the Aspen HYSYS simulation. Some equipment and operating costs are also provided by the recycling company who is currently constructing a $100 \mathrm{~kg} / \mathrm{h}$ pilot plant. These include equipment purchase costs of the combustor, pyrolysis reactor and HVF, as well as the plant labour costs. The UK is set as the default country since it has defined economic parameters in APEA, such as equipment costs and utilities ${ }^{37}$. The assumptions and economic inputs used in APEA are provided in Table 2 . The utility costs for the water used in the heat exchangers are considered to be zero because the condensation system is a closed loop. The plastic waste feedstock cost is zero as it is assumed that the local authorities do not pay any waste disposal fees to the owners of the pyrolysis plant $^{38}$.

Table 2: Economic inputs to Aspen Process Economic Analyzer (APEA)

\begin{tabular}{ll}
\hline General investment parameters & \\
\hline Base year & 2013 \\
Plant life & 20 years \\
Plant annual operating hours & 7012 \\
Tax rate & $40 \%{ }^{\mathrm{a}}$ \\
Interest rate & $10 \%{ }^{\mathrm{a}}$ \\
Working capital & $5 \%$ of $\mathrm{TCI}^{\mathrm{a}}$ \\
Maintenance & $10 \%$ of TCI \\
\hline Raw material cost and product sales & $0.55 £ / \mathrm{kg}^{\mathrm{b}}$ \\
\hline Pyrolysis fuel product sale price & \\
\hline Utility prices & $0.0576 £ / \mathrm{kWh}^{\mathrm{b}}$ \\
\hline Electricity & \\
\hline${ }^{\mathrm{a} A P E A ~ d e f a u l t ~ v a l u e s ~(c o u n t r y ~ b a s e: ~ U K) . ~}$ & \\
b Recycling company based in the UK, personal communication, 2014
\end{tabular}


The annuity techno economic assessment method is used in order to estimate the fuel production costs. The annual amount of the capital investment is assumed to be borrowed and repaid over the lifetime of the plant at the specified loan interest rate ${ }^{39}$ :

$$
A C I=T C I \times \frac{r \times(1+r)^{N}}{(1+r)^{N}-1}
$$

where ACI is the annuity of the capital investment, $r$ the interest rate and $\mathrm{N}$ the lifetime of the plant. The total capital investment (TCI) consists of installed direct equipment costs, indirect costs (e.g. engineering and supervision), tax and working capital ${ }^{37}$.

The total annual costs, i.e. ACI and operating costs need to be determined in order to estimate the fuel production costs. The operating costs include raw material (i.e. plastic waste feedstock), utilities, labour, and maintenance costs ${ }^{37}$. The fuel production costs are calculated by dividing the total annual costs by the annual pyrolysis fuel production:

$$
\text { Fuel production costs }=\frac{\text { ACI+Operating Costs }}{\text { Pyrolysis Fuel Annual Production }}
$$

The price inflation of capital, pyrolysis fuel, raw material, utilities, and labour costs are not considered for the calculation of the fuel production costs.

The above method allows for easy and quick comparisons with product market prices in order to preliminarily assess the profitability of the project. Its results are rather realistic as long as the inflation rate is not too different from the interest rate considered; however, it does not take into account diminution in the value of the incomes received or costs expended each year. Therefore, it was also decided to calculate the net present value (NPV) and pay-out period (PO) of the pyrolysis plant.

In contrast to the annuity method, the NPV method effectively accounts for the current value of all the net earnings received through the plant's life ${ }^{37}$ and thus can determine if the project is profitable at a higher accuracy. A discount rate (d) is introduced to represent the decrease in value of the earnings, because it is not paid at the time of the capital expense but a number of years later:

$$
N P V_{n}=\frac{\sum_{1}^{n} N C F}{(1+d)^{n}}
$$

where NCF is the net cash flow of the project, $\mathrm{d}$ the discount rate that the NCF is discounted to the year 0 and $n$ is the current year. The NCF is calculated by adding the depreciation expense to the Net Earnings (NE). Since the depreciation expense is a non-cash expense (in reality no cash leaves the facility in order to pay the depreciation expense), adding the depreciation to the NE gives the total cash flow obtained from the project.

$$
N E=(\text { Revenue }- \text { Depreciation Expence }) * \text { Taxes }
$$

The revenue of a plant is the amount of money available after capital and operating expenses have been paid and is obtained by subtracting capital costs and operating costs from sales. Exclusion of the depreciation expense from the revenue reduces the amount of taxable income. The depreciation expense, which is the amount that the capital cost is depreciated each year, is calculated by using the straight line method. This method assumes that the capital investment will depreciate by a constant amount over the life of the project. 
When the NPV is zero, the investor exactly recovers all their costs over the lifetime of the project. In case the NPV is positive, the investor's property will be increased by this value after the lifetime of the project. A negative NPV indicates that the project cannot be realised without taking losses and thus it is not economically feasible.

In addition to the NPV, the PO of the plant is also calculated. The PO is the number of years that the facility needs to operate to fully recover the capital investment and is obtained when the NPV is zero ${ }^{37}$.

Table 3 shows the price inflation of several economic parameters considered for the calculation of revenue, NPV and PO.

Table 3: Inflation inputs to Aspen Process Economic Analyser (APEA)

\begin{tabular}{ll}
\hline Inflation (\% per year) $^{\mathrm{a}}$ & \\
\hline Project Capital Inflation & 5 \\
Products Inflation & 5 \\
Raw Material Inflation & 3.5 \\
Operating and Maintenance Labour Inflation $^{\text {Utilities Inflation }}$ & 3 \\
Project Capital Inflation $^{\text {a }}$ & 3 \\
Depreciation Method $^{\mathrm{a}}$ & 5 \\
\hline Salvage Value (Fraction of Initial Capital Cost) $^{\mathrm{a}}$ & Straight Line \\
\hline Discount Rate (\% per year) $^{\mathrm{a}}$ & 20 \\
\hline${ }^{\mathrm{a}}$ APEA default values (country base: UK). & 20 \\
\hline
\end{tabular}

\section{Results and discussion}

\subsection{Mass and energy balances}

Figure 2 presents the mass and energy balances of the $100 \mathrm{~kg} / \mathrm{h}$ plastic waste plant. The major energy input of the plant is plastic waste which corresponds to $1224 \mathrm{~kW}\left(\mathrm{LHV}_{\mathrm{dry}}\right)$. The pyrolysis plant produces $85.8 \mathrm{~kg} / \mathrm{h}$ of fuel $\left(1055 \mathrm{~kW}, \mathrm{LHV}_{\text {dry }}\right)$. This corresponds to mass yields of $85.8 \%$, which is in agreement with literature ${ }^{11-14}$. The fuel energy efficiency is also calculated by dividing the energy in the pyrolysis fuel output by the energy content of the plastic waste. This represents the fraction of the energy in plastic waste which is retained in the fuel product and is calculated at $86 \%\left(\operatorname{LHV}_{\mathrm{dry}}\right)$.

Pyrolysis is an endothermic reaction requiring a constant source of energy. In the examined pyrolysis process, this thermal energy is provided by combusting the pyrolysis by-products (i.e. char, noncondensable gases). The available thermal energy from burning char and the non condensable gases is calculated by Aspen HYSYS as $156.7 \mathrm{~kW}_{\text {th. }}$. As discussed in Section 3.1 the total thermal energy for the pyrolysis reactor, is approximately $41.16 \mathrm{~kW}_{\text {th }}$; therefore, an external heating source is not required.

However, external electricity inputs are needed to operate equipment, such as air blowers and water pumps, as well as, light plant buildings. The overall plant electricity requirements are calculated by the simulator and it amounts to $36 \mathrm{~kW}_{\mathrm{e}}$. Steam can be generated, if necessary, by utilising flue gases from the combustion of the pyrolysis by-products, generating up to $115.6 \mathrm{~kW}_{\text {th }}$. Start-up energy requirements, such as natural gas, to initially fire the combustion reactor until it reaches the required temperature have not been taken into account.

\subsection{Economic analysis}

\subsubsection{Base case}


Table 4 summarises the cost results for the base case scenario $(100 \mathrm{~kg} / \mathrm{h}$ scale). The capital costs and operating expenditure are estimated by APEA and are $£ 999,492$ and $£ 416,325$, respectively. The fuel production costs are $0.87 £ / \mathrm{kg}$ and are calculated following the methodology described in Section 4 . An initial comparison of the fuel production costs with the fuel sale price $(0.55 £ / \mathrm{kg}$, see Table 2$)$ reveals that the project is not profitable at this scale.

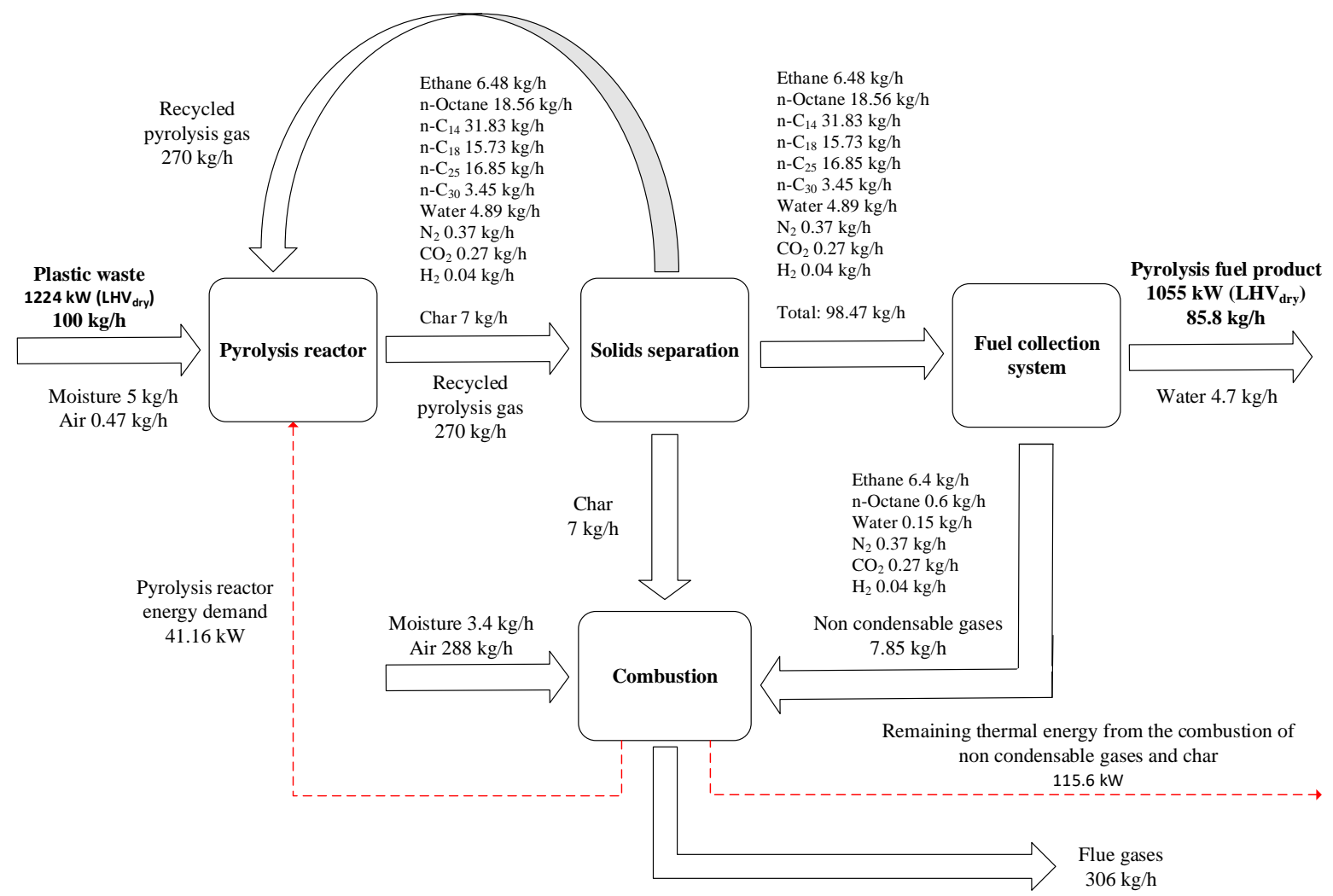

Figure 2: Summary of mass and energy balances

Table 4: Economic results for the base case pyrolysis plant (100 kg/h plastic waste) evaluated in this study

\begin{tabular}{lll}
\hline Cost & & Unit \\
\hline Total capital investment & 999,492 & $£$ \\
Total operating costs & 416,325 & $£ /$ year \\
Total utilities costs & 14,685 & $£ /$ year \\
Total product sales & 330,896 & $£ /$ year \\
& & \\
Fuel production costs & 19.30 & $£ / G J$ \\
Fuel production costs & 0.87 & $£ / \mathrm{kg}$ \\
\hline
\end{tabular}

\subsubsection{Scaled-up cases}

The influence of economies of scale on the pyrolysis fuel production costs was examined using Aspen HYSYS and APEA. The mass yields and pyrolysis fuel energy efficiency of the entire system does not change with scaling-up. In this paper, the scale-up study investigates the economic benefits derived from economies of scale (i.e. production cost reductions due to expenditures, like labour and equipment, spreading out over more units of output $)^{39}$. Three different cases were considered with the following plant capacities: $1,000,10,000$ and $100,000 \mathrm{~kg}$ of plastic waste per hour. The total operating costs, as well as the total capital investment of the three scaled-up cases are shown in Figure 3 and 
Figure 4, respectively. The operating costs range from $£ 0.42$ (base case) to 9.9 million, while the total capital costs range from $£ 0.99$ (base case) to 56.7 million, which are both proportional to the plant capacity.

The depreciation expense was also calculated for the base case and the scale-up cases using the straight line method (mentioned in Section 4) and a salvage value of 20. For the base case scenario the capital investment is depreciated by $39,980 \mathrm{f} /$ year while for the $1,000 \mathrm{~kg} / \mathrm{h}$ case the depreciation is estimated as 122,239 £/year. For the 10,000 and $100,000 \mathrm{~kg} / \mathrm{h}$ case, the depreciation expense is $374,059 £ /$ year and 2,270,700 £/year, respectively.

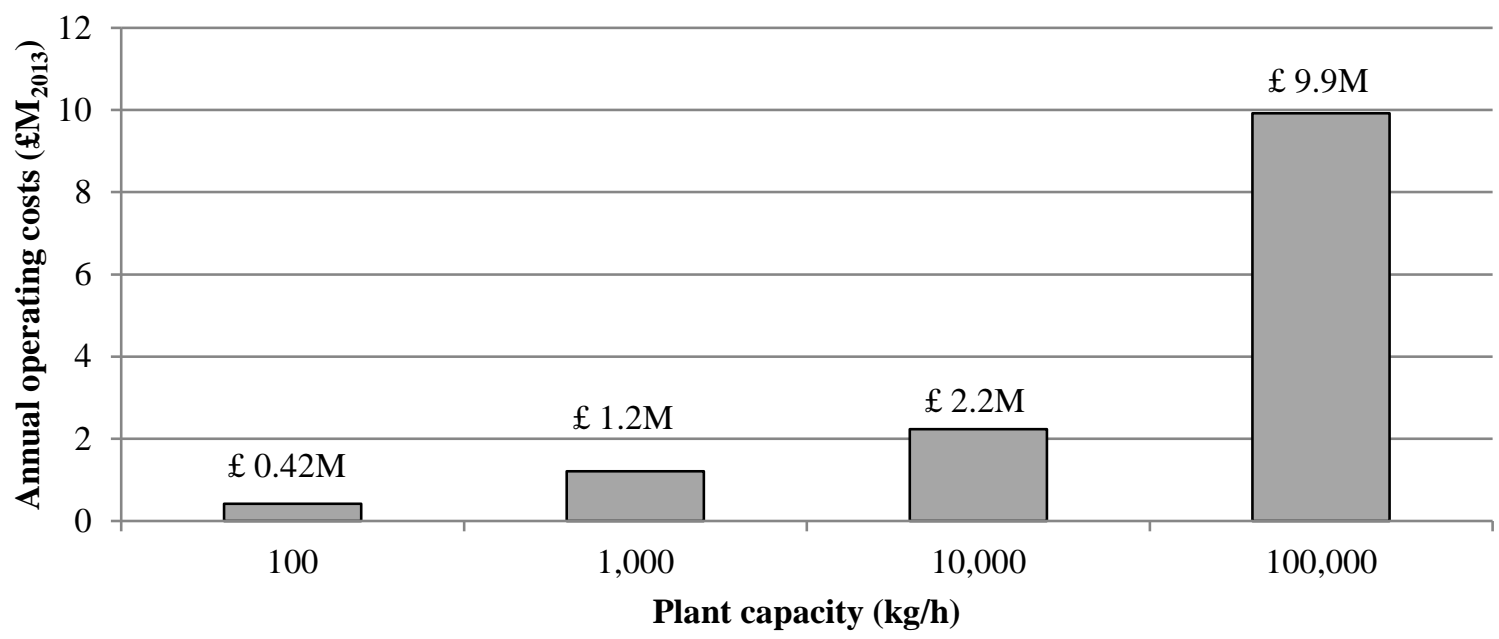

Figure 3: Total annual operating costs for the scaled-up cases.

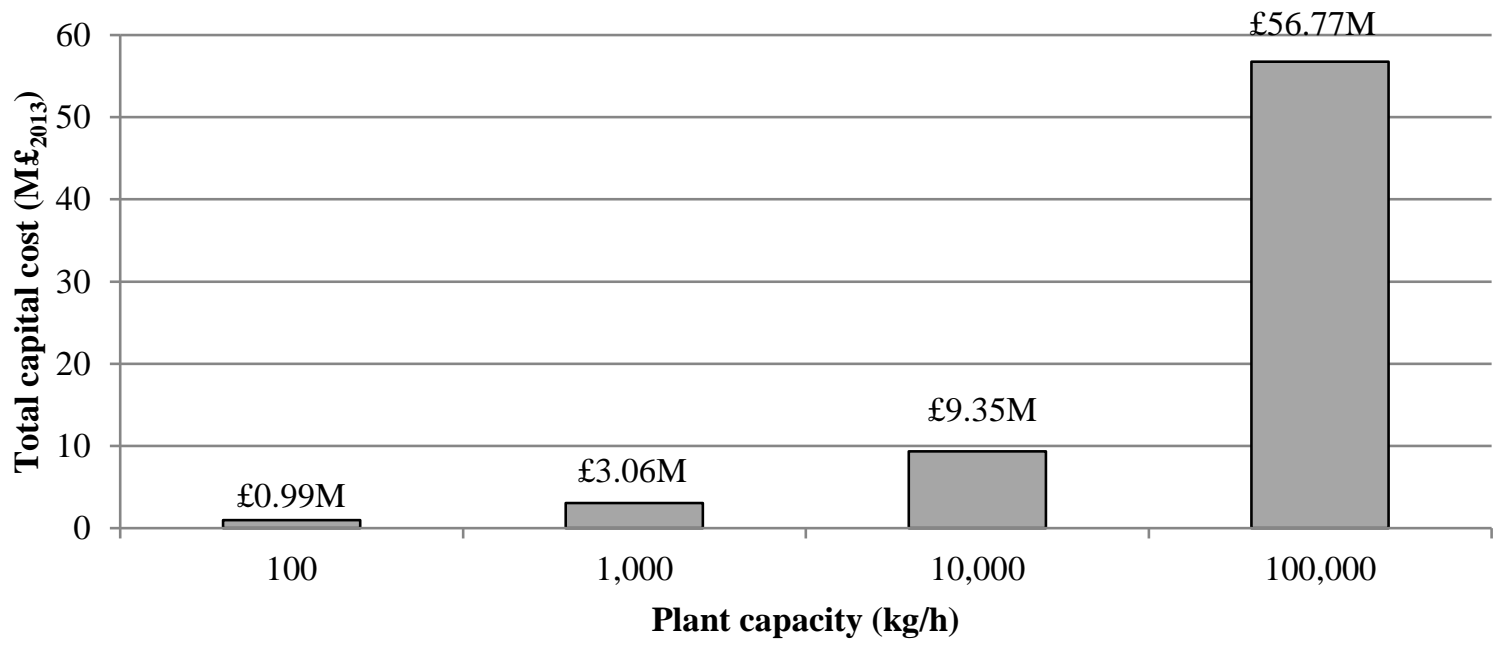

Figure 4: Total capital costs for the scaled-up cases.

Table 5 shows the operating, capital, and fuel production costs estimated by APEA for the scaled-up pyrolysis plants. For the plant processing $1,000 \mathrm{~kg}$ of waste per hour, the fuel production costs drop to $0.26 £ / \mathrm{kg}$, which is 2.16 times lower than that of the base case scenario $(0.87 £ / \mathrm{kg})$. This suggests that the process can be profitable at this capacity, since the respective fuel production cost of $0.26 £ / \mathrm{kg}$ is lower than the pyrolysis fuel sale price of $0.55 £ / \mathrm{kg}$ (see Table 2). The effect of economies of scale levels off for capacities above $20,833 \mathrm{~kg}$ per hour with much smaller cost reductions thereafter, as 
shown in Figure 5. In comparison, the pyrolysis fuel product sale price is $0.55 £ / \mathrm{kg}$, which is 2.16 , 10.28 , and 20.8 times higher than the pyrolysis fuel product production costs for the $1,000,10,000$, and $100,000 \mathrm{~kg} / \mathrm{h}$ case, respectively.

Table 5: APEA capital, operating and fuel production costs of the pyrolysis scaled-up plants in comparison with the base case.

\begin{tabular}{|c|c|c|c|c|}
\hline Plant capacity $(\mathrm{kg} / \mathrm{h})$ & $\begin{array}{c}100 \\
\text { (base case) }\end{array}$ & 1,000 & 10,000 & 100,000 \\
\hline Annual capital costs $(£ / k g)$ & 0.17 & 0.05 & 0.02 & 0.01 \\
\hline Operating costs $(\mathfrak{f} / \mathrm{kg})$ & 0.69 & 0.20 & 0.04 & 0.02 \\
\hline $\begin{array}{l}\text { Pyrolysis fuel product production } \\
\text { costs }(£ / \mathrm{kg})\end{array}$ & 0.87 & 0.26 & 0.05 & 0.03 \\
\hline
\end{tabular}

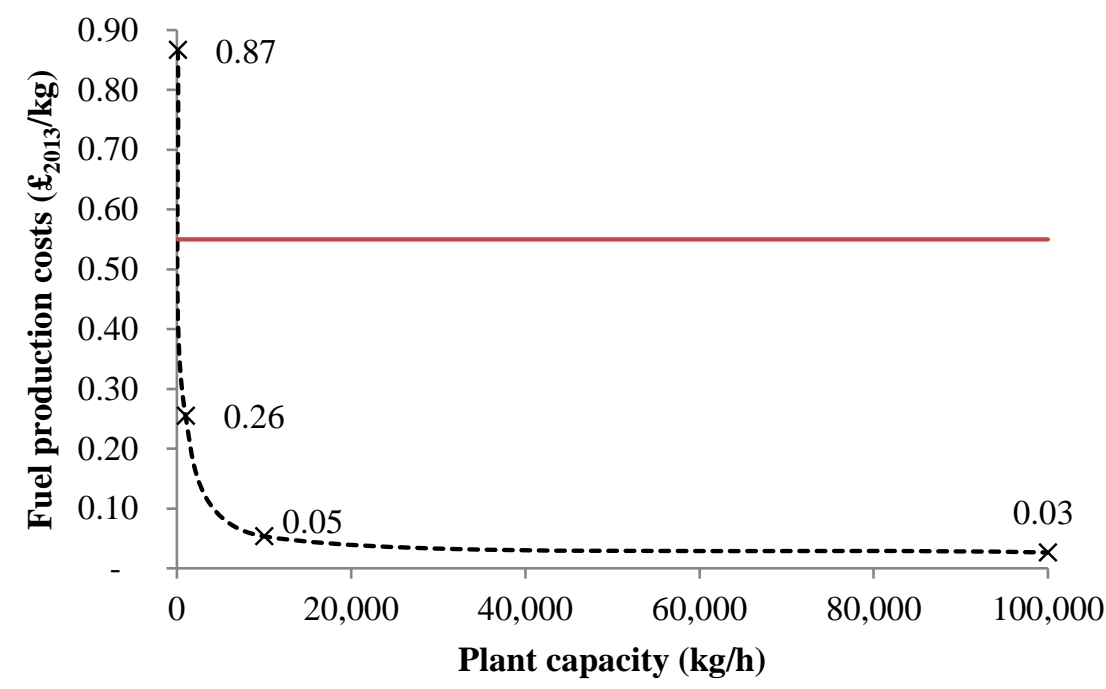

Figure 5: Fuel production costs in $£$ per kg for several pyrolysis plant capacities.

Figure 6 shows the revenue, NPV, and PO, estimated for each case. For the base case scenario, the plant shows revenue after year 11 ( $£ 661$ ), achieving revenue of $£ 126,000$ at the end of the plant's lifetime (year 20). The net present value is reduced after year 11; but it is not possible to achieve a positive value within the plant's life which indicates that this case is not economically viable. This is in agreement with the initial comparison of the base case production costs with the pyrolysis fuel product sale price (see section 5.2.1) which indicated that the base case scenario is not profitable within the plant's lifetime.

The PO period for the $1,000 \mathrm{~kg} / \mathrm{h}$ case is approximately four years. This agrees with Figure $6(\mathrm{~b})$ which shows that the NPV becomes positive $(£ 426,800)$ after year four of the plant's life, while the revenue ranges from $£ 2,360,859$ to $£ 6,588,169$. For the $10,000 \mathrm{~kg} / \mathrm{h}$ plant capacity, the pay-out period is only one year with a NPV of $£ 13,100,444$, while the $100,000 \mathrm{~kg} / \mathrm{h}$ case produces revenue and has a positive NPV (£3,454,892) within year one. Revenue ranges from $£ 34,111,594$ to $£ 83,762,343.82$ and $£ 4,820,169$ to $£ 860,051,038$, for each plant capacity respectively.

\subsection{Sensitivity analysis}

The fuel production costs can be affected by several key parameters, including the plant production rate $(\mathrm{kg} / \mathrm{h}$ of fuel), feedstock cost, loan interest rate, operating hours, capital costs, and electricity 
prices. The influence of these parameters on the base case $(100 \mathrm{~kg} / \mathrm{h})$ production costs is illustrated in Figure 7(a). The sensitivity analysis was carried out by changing each parameter in turn by $\pm 15 \%$ of its reference value (see Table 2). Longer bars indicate a higher degree of sensitivity to a specific key parameter. The reference value for fuel production costs is represented by the vertical line in the figure. The most sensitive parameter which has the greatest influence on the fuel production cost is the fuel production rate. This indicates that improving the pyrolysis process performance should be an early priority. The production costs can be reduced by $13.04 \%$, when the fuel production rate increases by $15 \%$ from 85.80 to $98.7 \mathrm{~kg} / \mathrm{h}$. High sensitivity is also observed to changes in plant operating hours, with a reduction of $6.68 \%$ on fuel production costs, when the annual operating hours are increased by $15 \%$ from 5,960 to 8,063 . Capital costs show a similar effect, since fuel production costs are reduced by approximately $7.69 \%$ with a decrease from $£ 999,492$ to $£ 849,568$, respectively. A lower sensitivity is also observed to changes in interest, with a reduction of $3.03 \%$ on fuel production costs, when the interest is decrease from $10 \%$ to $7 \%$.

(a) Base Case

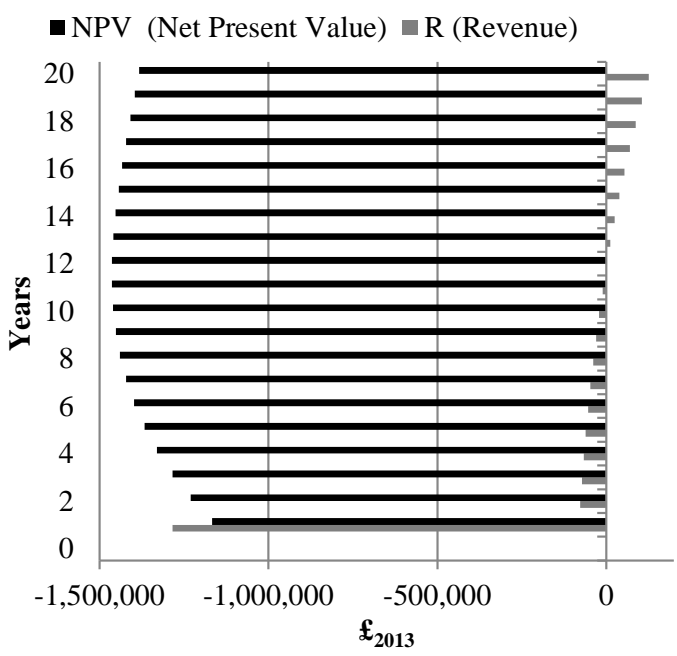

(c) $10,000 \mathrm{~kg} / \mathrm{h}$

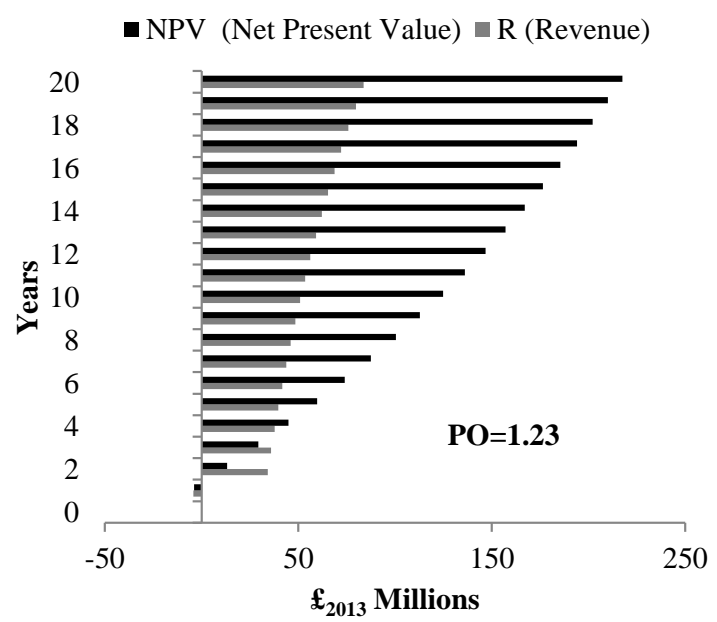

(b) $1,000 \mathrm{~kg} / \mathrm{h}$

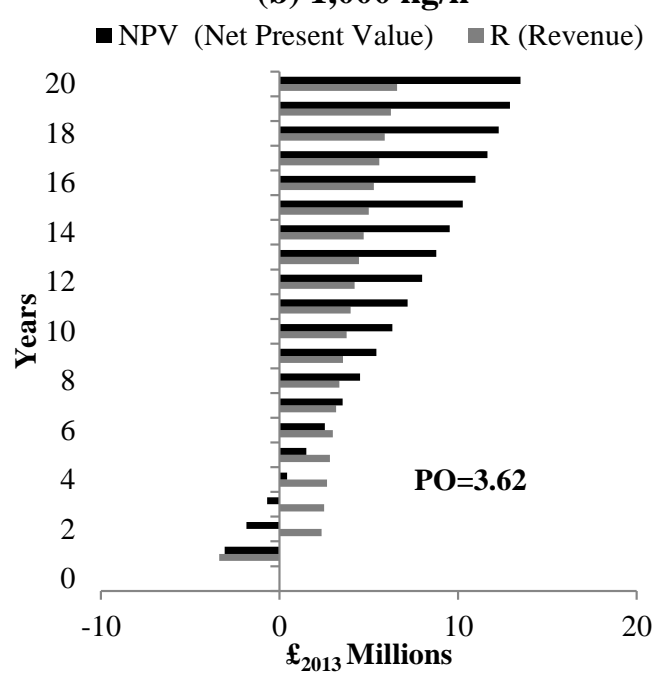

(d) $100,000 \mathrm{~kg} / \mathrm{h}$

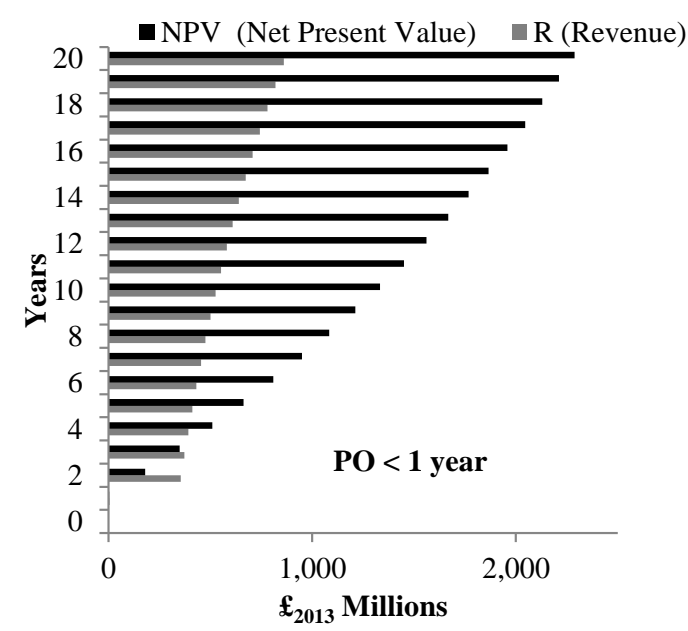

Figure 6: Revenue, NPV, and PO, estimated for the pyrolysis scaled-up plants in comparison with the base case. 
Figure 7(b), Figure 7(c), and Figure 7 (d) show the effect of the key parameters on the three scaled up cases with a capacity of $1,000 \mathrm{~kg}, 10,000 \mathrm{~kg}$, and $100,000 \mathrm{~kg}$ per hour. The sensitivity analysis shows that the fuel production rate is also the most sensitive parameter for these cases as a cost reduction of $13.03 \%$ to $13.04 \%$ is possible. Similar to the base case $(100 \mathrm{~kg} / \mathrm{h})$, the second most sensitive parameter is the plant operating hours followed by capital costs and interest, but their effect on fuel production cost is higher. A reduction in fuel production cost of $6.94 \%$ and $10.13 \%$ is achieved, when the operating hours are increased to 8,063 for the $1,000 \mathrm{~kg}$ and $10,000 \mathrm{~kg}$ per hour case, respectively. For the $100,000 \mathrm{~kg}$ per hour case, the reduction in fuel production cost is of $12.45 \%$. For the 1,000 $\mathrm{kg} / \mathrm{h}$ scenario, a $15 \%$ reduction in capital cost and interest results in a production cost decrease of $12.09 \%$ and $3.14 \%$, while for the $10,000 \mathrm{~kg} / \mathrm{h}$ case, the fuel production costs are reduced by $11.57 \%$ and $4.59 \%$, respectively. For the $100,000 \mathrm{~kg} / \mathrm{h}$ capacity, a $15 \%$ reduction in capital cost and interest results in a decrease of $14.45 \%$ and $5.64 \%$ in fuel production costs, respectively. For all cases, the effect of the electricity price on the fuel production costs is much lower compared to the other parameters due to the low electricity requirements of the pyrolysis plant.

(a) Base Case

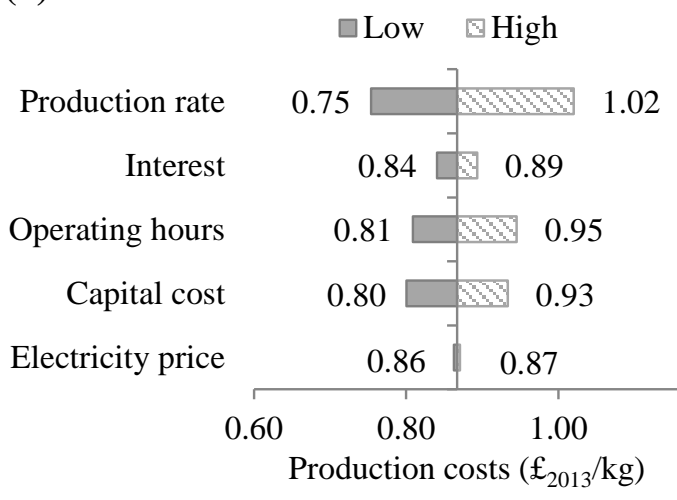

(c) $10,000 \mathrm{~kg} / \mathrm{h}$

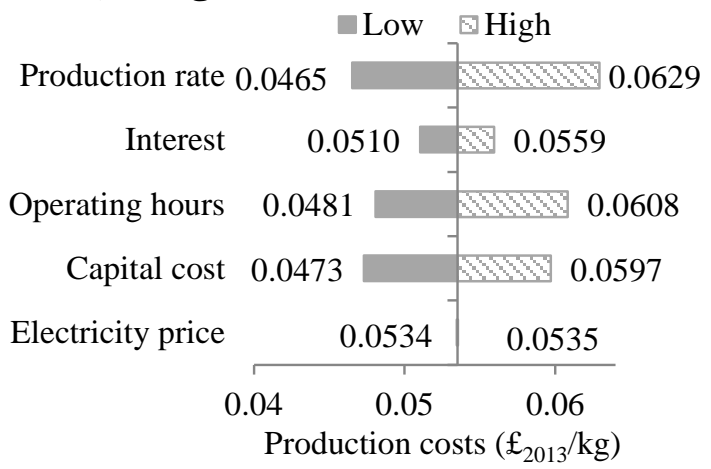

(b) $1,000 \mathrm{~kg} / \mathrm{h}$

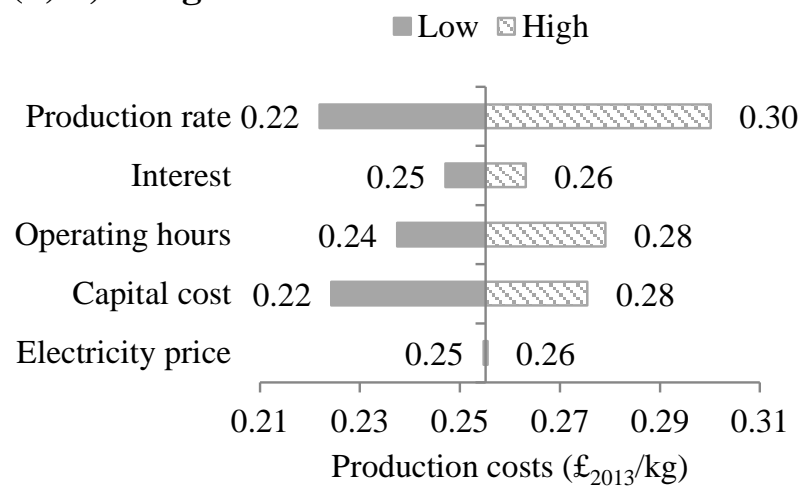

(d) $100,000 \mathrm{~kg} / \mathrm{h}$

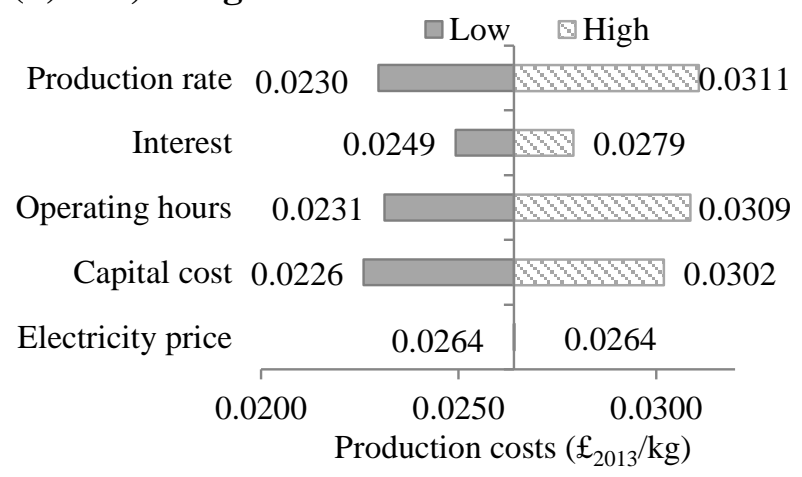

Figure 7: Sensitivity of fuel production costs to key process and economic parameters for the base case and the scaled-up scenarios.

A separate sensitivity analysis was carried out to examine the effect of waste disposal fees on fuel production costs. As discussed in section 4, the initial value of the plastic waste feedstock was set to zero as it was assumed that the plant owners did not receive any waste disposal fees from the local authorities. Figure 8 shows the effect of receiving waste disposal fees (i.e. negative feedstock costs) and the effect of paying to receive the waste (i.e. positive feedstock costs) on the pyrolysis fuel production costs for the base case and the scaled-up designs. For the base case scenario, the production costs can be reduced by $2.18 \%$ when the plastic waste costs decreases from zero to -0.015 
$£ / \mathrm{kg}$, and can be increased by $2.18 \%$ when the plastic waste costs increases from zero to $0.015 £ / \mathrm{kg}$. For the larger plant capacities, when the plastic waste costs decreases from zero to $-0.015 £ / \mathrm{kg}$, the effect of feedstock costs is higher, and a cost reduction of $7.4 \%, 35.3 \%$, and $66.18 \%$ can be achieved for the $1,000 \mathrm{~kg} / \mathrm{h}, 10,000 \mathrm{~kg} / \mathrm{h}$ and $100,000 \mathrm{~kg} / \mathrm{h}$ cases, respectively.

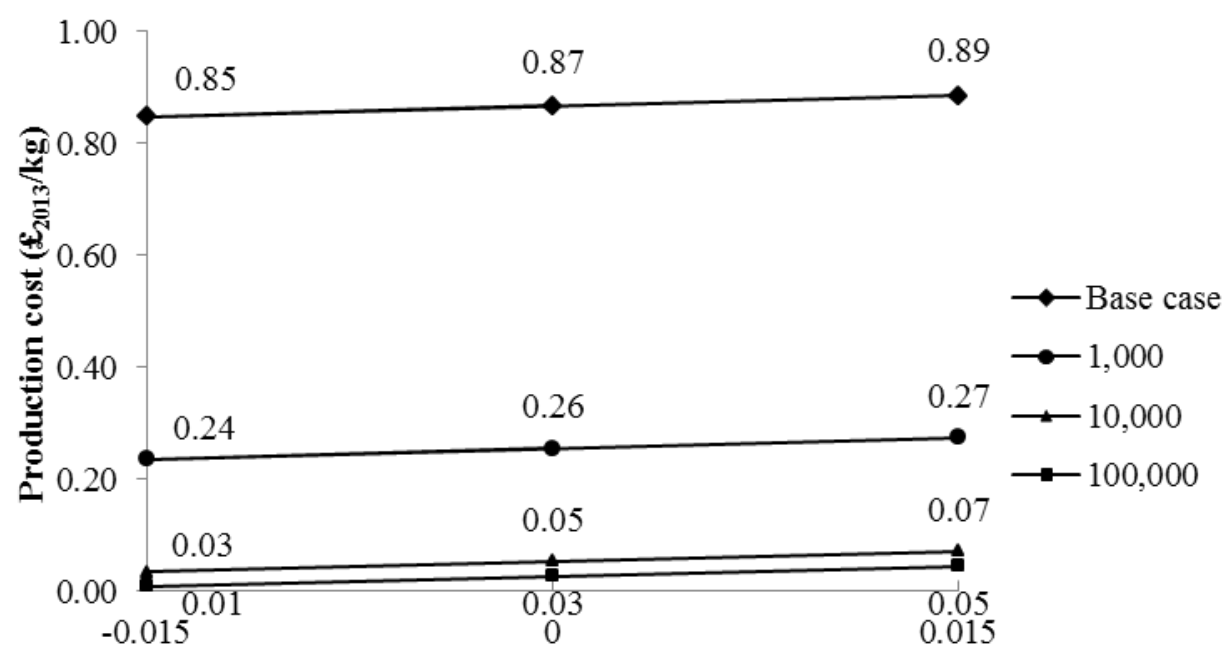

\section{Feedstock cost $\left(f_{2013} / \mathrm{kg}\right)$}

Figure 8: Sensitivity of fuel production cost to the feedstock cost for the base case and the scaled-up scenarios.

\section{Conclusions}

This study has investigated the technical and economic feasibility of a plastic waste pyrolysis process for the production of a heavy fuel oil substitute. The base case scenario considered is a plant with a capacity of $100 \mathrm{~kg} / \mathrm{h}$ of plastic waste, consisting ofa mixture of polyethylene, polypropylene, and polystyrene, which can effectively be converted into a wax/oil, as well as char and gases as value added products. The fuel energy efficiency is calculated by Aspen HYSYS at $86 \%$ (LHV dry $_{\text {ry }}$. Results show that the process does not require an external heating source (e.g. natural gas) since the total thermal energy required by the pyrolysis reactor $(41.16 \mathrm{kWth})$ does not exceed the energy from burning the pyrolysis char and gases (156.7 kWth).

Using the annuity method, the fuel production cost is calculated at $0.87 £ / \mathrm{kg}$, which is $58 \%$ higher than the pyrolysis fuel product sale price $(0.55 £ / \mathrm{kg}$ in 2013$)$. The effect of economies of scale on the fuel production costs is also investigated by considering three different plant capacities: 1000, 10,000 and $100,000 \mathrm{~kg} / \mathrm{h}$ of plastic waste feed. The fuel production costs of the larger plastic waste pyrolysis plants are about 2.2-20.8 times lower than the pyrolysis fuel product sale price, indicating the economic feasibility of the plastic waste pyrolysis process for plant capacities above $1,000 \mathrm{~kg} / \mathrm{h}$.

The revenue, net present value (NPV) and pay-out (PO) period are also estimated for the base case and the three pyrolysis scaled-up plants. For the base case scenario, the NPV is negative throughout the lifetime of the plant (20 years) which suggests that this case is not economically feasible. The PO period for the $1,000 \mathrm{~kg} / \mathrm{h}$ case is approximately four years. For the $10,000 \mathrm{~kg} / \mathrm{h}$ plant capacity, the pay-out period is only one year, while the $100,000 \mathrm{~kg} / \mathrm{h}$ case produces revenue and has a positive NPV within year one.

The sensitivity analysis reveals that the fuel production costs are mainly influenced by variations in the fuel production rate, operating hours, interest rate and capital investment. The fuel production rate 
is the most sensitive parameter for all cases. For the base case scenario, the production costs can be reduced by $13.04 \%$ when the fuel production rate increases from 85.80 to $98.7 \mathrm{~kg} / \mathrm{h}$, while for the larger plant capacities a cost reduction of $6.94 \%$ to $12.45 \%$, can be achieved.

A separate sensitivity analysis was carried out to examine the effect of waste disposal fees on fuel production costs. For the base case scenario, the production costs can be reduced by $2.18 \%$ when the plastic waste costs decreases from zero to $-0.015 £ / \mathrm{kg}$, while for the larger plant capacities a cost reduction of $7.4 \%$ to $66.18 \%$, can be achieved.

\section{ACKNOWLEDMENTS}

The authors gratefully acknowledge the University of Sheffield for supporting this work financially.

\section{REFERENCES}

\footnotetext{
${ }^{1}$ PlasticsEurope 2014/2015: An analysis of European plastics production, demand, and waste data.

${ }^{2}$ Gordon McKay, Dioxin characterisation, formation and minimisation during municipal solid waste (MSW) incineration: review, Chemical Engineering Journal 86 (2002) 343-368

${ }^{3}$ Qinghai Li, Aihong Meng, Jinyan Jia, Yanguo Zhang, Investigation of heavy metal partitioning influenced by flue gas moisture and chlorine content during waste incineration, Journal of Environmental Sciences 2010, 22(5) 760-768.

${ }^{4}$ Jambeck, J.R., Geyer, R., Wilcox, C., Siegler, T.R., Perryman, M., Andrady, A., Narayan, R., Law, K.L., 2015. Plastic waste inputs from land into the ocean. Science 347, 768-771.

${ }^{5}$ EC, 2015a. Proposal for a Directive of the European Parliament and of the Council Amending Directive 2008/98/EC on Waste, COM (2015) 595. European Commission (EC), Brussels, Belgium.

${ }^{6}$ EC, 2015b. Proposal for a Directive of the European Parliament and of the Council Amending Directive 94/62/EC on Packaging and Packaging Waste, COM (2015) 596. European Commission (EC), Brussels, Belgium.

${ }^{7}$ Ignatyev, I.A., Thielemans, W., Vander Beke, B., 2014. Recycling of polymers: a review. ChemSusChem 7 , 1579-1593.

${ }^{8}$ W. Kaminsky, M. Predel, A. Sadiki , Feedstock recycling of polymers by pyrolysis in a fluidised bed, Polymer Degradation and Stability 85 (2004) 1045-1050.

${ }^{9}$ F. Pinto, P. Costa, I. Gulyurtlu, I. Cabrita, Pyrolysis of plastic wastes. 1. Effect of plastic waste composition on product yield, Journal of Analytical and Applied Pyrolysis 51 (1999) 39-55.

${ }^{10}$ Jingxuan Yang, Jenny Rizkiana, Wahyu Bambang Widayatno, Surachai Karnjanakom, Malinee Kaewpanha, Xiaogang Hao, Abuliti Abudula, Guoqing Guan, Fast co-pyrolysis of low density polyethylene and biomass residue for oil production, Energy Conversion and Management, Volume 120, 15 July 2016, Pages 422-429.

${ }^{11}$ F. Gao, Pyrolysis of waste plastics into fuels, PhD thesis, University of Canterbury, New Zealand (2010).

${ }^{12}$ A. Aboulkas, K. El harfi, A. El Bouadili, Thermal degradation behaviors of polyethylene and polypropylene. Part I: Pyrolysis kinetics and mechanisms, Energy Conversion and Management, Volume 51, Issue 7, July 2010, Pages 1363-1369.

${ }^{13}$ Walendziewski, J 2005, 'Continuous flow cracking of waste plastics', Fuel Processing Technology, vol. 86, pp. 1265-1278.

${ }^{14}$ Yirong Liu, Jialin Qian, Jianqiu Wang, Pyrolysis of polystyrene waste in a fluidized-bed reactor to obtain styrene monomer and gasoline fraction, Fuel Processing Technology, Volume 63, Issue 1, March 2000, Pages 45-55.

15 Williams, PT \& Williams, EA 1999, 'Fluidised bed pyrolysis of low density polyethylene to produce petrochemical feedstock', Journal of Analytical and Applied Pyrolysis, vol. 51, pp. 107-126.

${ }^{16}$ R. Miandad, A.S. Nizami, M. Rehan, M.A. Barakat, M.I. Khan, A. Mustafa, I.M.I. Ismail, J.D. Murphy, Influence of temperature and reaction time on the conversion of polystyrene waste to pyrolysis liquid oil, Waste Management, Volume 58, December 2016, Pages 250-259.

${ }^{17}$ Syamsiro, M., Saptoadi, H., Norsujianto, T., Noviasri, Cheng S., Alimuddin, Z., Yoshikawa, K., 2014. Fuel oil production from municipal plastic wastes in sequential pyrolysis and catalytic reforming reactors. Energy Procedia 4, 180e188.

Tekin, K., Akalın,
} 
${ }^{18}$ Sahu, J.N., Mahalik, K.K., Nam, H. K., Ling, T. Y., Woon, T. S., bin Abdul Rahman, M. S., Mohanty, Y.K., Jayakumar, N.S. and Jamuar, S.S. (2014), Feasibility study for catalytic cracking of waste plastic to produce fuel oil with reference to Malaysia and simulation using ASPEN Plus. Environ. Prog. Sustainable Energy, 33: 298307.

${ }^{19}$ A. Sayal, V. K. Sangal, P. Singh, 2014, Simulation Study for Production of Hydrocarbons from Waste. American Journal of Engineering Research (AJER),vol.3, issue 11, pp. 251-259.

${ }^{20}$ PlasticsEurope, EuPC, EuPR, EPRO and Consultic (2009) The Compelling Facts about Plastics - An analysis of European plastics production, demand and recovery for 2008.

${ }^{21}$ Faravelli, T., Pinciroli, M., Pisano, F., Bozzano, G., Dente, M., Ranzi, E., 2001. Thermal degradation of polystyrene. J. Anal. Appl. Pyrolysis 60, 103e121.

${ }^{22}$ F.J. Mastral, E. Esperanza, P. Garcia, M. Juste, 2002. Pyrolysis of high-density polyethylene in a fluidised bed reactor. Influence of the temperature and residence time. Analytical and Applied Pyrolysis, vol. 63, 1, pp.1-15.

${ }^{23}$ L. Sorum, M.G. Gronli, J.E. Hustad, 2001. Pyrolysis characteristics and kinetics of municipal solidwastes. Fuel, 80, pp. 1217-1227

${ }^{24}$ A. Aboulkas, K. El-harfi, and A. El-Bouadili. "Thermal degradation behaviours of polyethylene and polypropylene. Part I: Pyrolysis kinetics and mechanisms". Energy Conversion and Management, vol. 51, pp. 1363-1369, 2010.

${ }^{25}$ Su-Hwa Jung, Min-Hwan Cho, Bo-Sung Kang, Joo-Sik Kim, 2010. Pyrolysis of a fraction of waste polypropylene and polyethylene for the recovery of BTX aromatics using a fluidized bed reactor. Fuel Processing Technology 91,(3), pp.277-284.

${ }^{26}$ A.V. Bridgwater, Review of fast pyrolysis of biomass and product upgrading, Biomass and Bioenergy, Volume 38, 2012, Pages 68-94, ISSN 0961-9534, http://dx.doi.org/10.1016/j.biombioe.2011.01.048.

${ }^{27}$ M. Arabiourrutia, G. Elordi, G. Lopez, E. Borsella, J. Bilbao, M. Olazar, Characterization of the waxes obtained by the pyrolysis of polyolefin plastics in a conical spouted bed reactor, Journal of Analytical and Applied Pyrolysis, Volume 94, 2012, Pages 230-237, ISSN 0165-2370, http://dx.doi.org/10.1016/j.jaap.2011.12.012.

${ }^{28}$ R.H. Perry, D.W. Green, and J.O. Maloney. Perrys Chemical Engineers Handbook. McGraw-Hill, New York, 7th edition, 1997.

${ }^{29}$ Aspen Technology, Aspen Hysys Version 8.6, Burlington, MA, USA, 2013.

${ }^{30}$ Aspen Technology, Aspen Physical Property System - Physical Property Methods, Burlington, USA, 2013.

${ }^{31}$ Aihong Meng, Shen Chen, Yanqiu Long, Hui Zhou, Yanguo Zhang, Qinghai Li, Pyrolysis and gasification of typical components in wastes with macro-TGA, Waste Management, Volume 46, December 2015, Pages 247256.

${ }^{32}$ Adetoyese Olajire Oyedun, Tesfaldet Gebreegziabher, Denny K.S. Ng, Chi Wai Hui, Mixed-waste pyrolysis of biomass and plastics waste, A modelling approach to reduce energy usage, In Energy, Volume 75, 2014, Pages 127-135, ISSN 0360-5442, https://doi.org/10.1016/j.energy.2014.05.063

${ }^{33}$ Channiwala, S.A. and P.P. Parikh, A unified correlation for estimating HHV of solid, liquid and gaseous fuels. Fuel, 2002.81(8): p. 1051-1063.

${ }^{34}$ Jayeeta Chattopadhyay, T.S. Pathak, R. Srivastava, A.C. Singh, Catalytic co-pyrolysis of paper biomass and plastic mixtures (HDPE (high density polyethylene), PP (polypropylene) and PET (polyethylene terephthalate)) and product analysis, In Energy, Volume 103, 2016, Pages 513-521, ISSN 0360-5442, https://doi.org/10.1016/j.energy.2016.03.015.

${ }^{35}$ Yuan, X., Converting Waste Plastics into Liquid Fuel by Pyrolysis: Developments in China, in Feedstock Recycling and Pyrolysis of Waste Plastics, J. Scheirs and W. Kaminsky, Editors. 2006, John Wiley \& Sons, Ltd: Changsha, P.R. China. p. 729-755.

${ }^{36}$ Nilgun Kiran Ciliz, Ekrem Ekinci, Colin E. Snape, Pyrolysis of virgin and waste polypropylene and its mixtures with waste polyethylene and polystyrene, Waste Management, Volume 24, Issue 2, 2004, Pages 173 181, ISSN 0956-053X, https://doi.org/10.1016/j.wasman.2003.06.002.

${ }^{37}$ Aspen Technology, Aspen Icarus Reference Guide - Icarus Evaluation Engine (IEE), Burlington, USA, 2013.

${ }^{38}$ Recycling company based in the UK, personal communication, 2014.

${ }^{39}$ I. Dimitriou, P. Garcia-Gutierrez, R. H. Elder, R. M. Cuellar-Franca, A. Azapagic and R. W. K. Allen, Energy Environ. Sci., 2015, 8, 1775-1789. 